\title{
Commentary: Heroes of the arterial switch operation in the 1980s
}

\author{
Osman O. Al-Radi, MBBCh, MSs, FRCSC
}

\author{
From the Faculty of Medicine, Department of Surgery, King Abdulaziz University, Jeddah, Saudi Arabia. \\ Disclosures: Author has nothing to disclose with regard to commercial support. \\ Received for publication Aug 31, 2019; revisions received Aug 31, 2019; accepted for publication Sept 3, 2019; \\ available ahead of print Oct 10, 2019. \\ Address for reprints: Osman O. Al-Radi, MBBCh, MSs, FRCSC, Faculty of Medicine, Department of Surgery, \\ King Abdulaziz University, Jeddah, Saudi Arabia (E-mail: oradi@kau.edu.sa). \\ J Thorac Cardiovasc Surg 2020;159:617-8 \\ $0022-5223 / \$ 36.00$ \\ Copyright (C) 2019 by The American Association for Thoracic Surgery \\ https://doi.org/10.1016/j.jtcvs.2019.09.011
}

It is said that history is written by-and for-the victors. Medical literature, with a similar bias, is written for the survivors. In this issue of the Journal, Jegatheeswaran and colleagues ${ }^{1}$ write about the outcome of a story that started in 1976 , when Jatene and colleagues ${ }^{2}$ reported the first survivor of the arterial switch operation for transposition of the great arteries. We live today in the era of $2 \%$ operative mortality associated with the arterial switch operation. ${ }^{3}$ And, as reported by Jegatheeswaran and colleagues, ${ }^{1}$ the parents today are led to expect normal perception of health and functional outcomes out to 20 years of follow-up. The study included 868 patients who met the eligibility criteria for the study. Most had a simple form of transposition with or without a ventricular septal defect. The patients who responded to the self-administered quality of life questionnaire had perceptions of health basically similar to those of people of the same age.

This is the happy ending to the story. We, the third generation of congenital heart surgeons, who trained after the turn of the millennium, have missed the real battle that our predecessors (surgeons of the 1980s and 1990s) fought to get us to where we are today. This battle was, to say the least, a technical, professional, and emotional test for all. These surgeons are our heroes, upon whose shoulders we stand. The true heroes, though, are the babies and their families, who took the biggest risk and unfortunately in some cases made the ultimate sacrifice. Let this be a moment for us to remember and honor their memory. And let this piece of medical literature be written for those who did not survive. To realize how difficult those times were, one has to imagine being the surgeon who has done hundreds of Mustard or Senning operations with outstanding results, reaching $1 \%$ operative mortality, with the prospect of normal health for many years. Imagine the dilemma of discussing with weary parents a new operation that is technically difficult, and one that you yourself are still trying to perfect-all this in hopes of a possibly better outcome 20 or 30 years down the road. You would also feel obliged to tell the parents that some of the handful of babies on

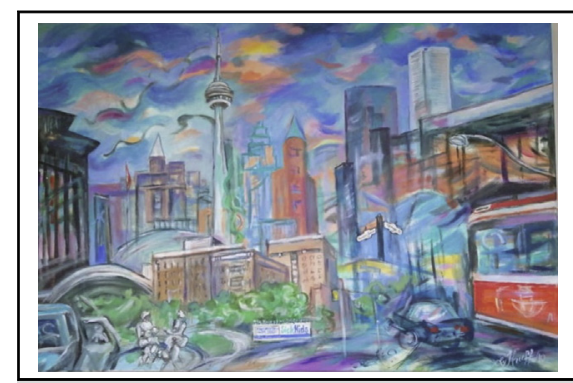

The Hospital for Sick Children, Toronto, Ontario, Canada. Artist's rendition.

\section{Central Message}

Medical literature is written about survivors; this is written in honor of the true heroes of the arterial switch operation.

See Article page 604.

whom you have done this operation did not survive. Remember, at this time, you-and everyone else for that matter-do not know how bad the Mustard or Senning outcomes are going to turn out to be and how good the arterial switch operation outcomes are ultimately going to be. As a surgeon, you have to justify your recommendations to the parents, who in most cases are laypeople susceptible to the way you say things to them. You also have to justify your decision to attempt this novel operation to your colleagues: other surgeons, anesthesiologists, cardiologists, and others. You must also be able to look into the eyes of the nurses who will take care of the baby in the intensive care unit, nurses who have recently suffered with you the loss of some of the previous babies who underwent this operation. This scenario may ring true for many new operations or technique modifications, but nowhere in congenital cardiac surgery has the contrast between old and new been so stark and the mountain to climb so high and rugged, because nowhere in congenital cardiac surgery does every bite of every anastomosis matter so much as it does in the arterial switch operation. It is an operation that is as artistic as it is unforgiving. To get a sense of how real this story is, you need not look beyond the rather carefully worded sentence in the article of Jegatheeswaran and colleagues ${ }^{1}$ where they state, "At the time of SF-36 administration (January 2010-October 2010), 659 of the 868 patients were not known to be dead." That is to say, the rest of the patients-209, or $24 \%$ — are known to be dead. It is fair 
to assume that many of these deaths were related to the operation.

Have we reached the end of innovation for the arterial switch, though? In other words, is the arterial switch a truly curative operation? Well, it is close, but not quite. There remain some issues that are emerging from the literature. In the medium term, 2 to 10 years out, most of what is reported is related to suprapulmonary stenosis and branch pulmonary artery stenosis. ${ }^{4}$ These are largely avoidable technical issues related to great vessel size mismatch, the material used to reconstruct the neo-pulmonary root, suturing technique or material, or a combination of these or other factors. One factor that is not reported as much but may play an important role is the stretch put on the pulmonary arteries as a result of the LeCompte maneuver, which is a modifiable factor.

In reports of long-term outcomes, additional issues have been reported, namely, aortic root dilatation, aortic valve insufficiency, and coronary artery problems. ${ }^{5,6}$ Though all these are reported, they are surprisingly infrequent. Is this because it is still too soon, and the prevalence will increase as more patients reach adulthood and older age? Aortic root dilatation and aortic insufficiency have several possible causes, including but not limited to the cellular and intercellular matrix differences between the aortic and pulmonary arterial walls and valve tissues. They may also be related to modifiable factors, however, such as disruption of the sinotubular junction or oversized sinuses of Valsalva as a result of the trapdoor technique of coronary anastomosis. Coronary issues are also surprisingly, and thankfully, even less prevalent. The effects of coronary anastomotic technique or suture material or coronary placement in or above the sinuses are currently unknown and remain to be elucidated by future research.

At least theoretically speaking, shortening the neoaorta before anastomosing it to the ascending aorta reduces the stretch on the pulmonary arteries and pulls the neo-aortic root more superiorly, so that the coronary anastomosis can be placed below the sinotubular junction in the true sinuses of Valsalva of the neo-aortic root. In addition, doing a punch-out rounded anastomosis for the coronaries causes less distortion of the neo-aortic root and sinotubular junction than does a large trapdoor or L-shaped anastomosis. ${ }^{7}$ Having said that, the potential long-term gain should not be favored relative to the short-term results, that is, survival. Surgeons must do what they do best. There is still much to be learned about the arterial switch operation and its long-term outcomes, and potential technical tweaks are to be expected. Incremental improvements in the arterial switch operation techniques may further improve late results. Meanwhile, today's patients with transposition of the great arteries and their families can be assured that their functional health status as young adults is likely to be very similar to that of their age-mates with normal anatomy.

The author acknowledge the preview of the manuscript by Dr William G. Williams to ensure accuracy of the historical record.

\section{References}

1. Jegatheeswaran A, Devlin PJ, DeCampli WM, Welke KF, Williams WG, Blackstone $\mathrm{EH}$, et al. Longitudinal functional health status in young adults with repaired dextro-transposition of the great arteries: a Congenital Heart Surgeons' Society study. J Thorac Cardiovasc Surg. 2020;159:604-14.e3.

2. Jatene AD, Fontes VF, Paulista PP, Souza LC, Neger F, Galantier M, et al. Anatomic correction of transposition of the great vessels. J Thorac Cardiovasc Surg. 1976;2:364-70.

3. Jacobs JP1, Mayer JE Jr, Pasquali SK, Hill KD, Overman DM, St Louis JD, et al. The Society of Thoracic Surgeons congenital heart surgery database: 2019 update on outcomes and quality. Ann Thorac Surg. 2019;107:691-704.

4. Lee J, Abdullah Shahbah D, El-Said H, Rios R, Ratnayaka K, Moore J. Pulmonary artery interventions after the arterial switch operation: unique and significant risks. Congenit Heart Dis. 2019;14:288-96.

5. van der Palen RLF, van der Bom T, Dekker A, Tsonaka R, van Geloven N, Kuipers IM, et al. Progression of aortic root dilatation and aortic valve regurgitation after the arterial switch operation. Heart. July 10, 2019 [Epub ahead of print].

6. Nakayama Y, Shinkawa T, Matsumura G, Hoki R, Kobayashi K, Niinami H. Late neo-aortic valve regurgitation long after arterial switch operation. Ann Thorac Surg. 2019;108:1210-6.

7. Al-Radi OO. Aortic ring autograft for reconstruction of the neo-pulmonary root in the arterial switch operation. J Thorac Cardiovasc Surg. 2016;151:e89-91. 